Original article

\title{
Risk factors for major low anterior resection syndrome: meta-analysis and systematic literature review
}

\author{
Evgeny A. Khomyakov ${ }^{1,2}$, Islam O. Nafedzov ${ }^{1}$, Oksana Y. Fomenko ${ }^{1}$, Mikhail V. Alekseyev ${ }^{1,2}$, Sergey A. Frolov ${ }^{1}$, \\ Stanislav V. Tchernyshov ${ }^{1}$, Evgeny G. Rybakov ${ }^{1}$ \\ ${ }^{1}$ A.N. Ryzhikh National Medical Research Center of Coloproctology, Moscow, Russia \\ ${ }^{2}$ Russian Medical Academy of Continuing Professional Education, Moscow, Russia
}

Received 13 February 2020, Revised 25 April 2020, Accepted 3 August 2020

(C) 2020, Khomyakov E.A., Nafedzov I.O., Fomenko O.Yu., Alekseyev M.V., Frolov S.A., Tchernyshov S.V., Rybakov E.G.

(C) 2020, Russian Open Medical Journal

Abstract: Introduction - Low anterior resection syndrome (LARS) is a socially significant problem that impedes social adaptation and contributes to deterioration of life quality in patients.

The objective of this study was to search for the category of patients most prone to major LARS, as well as to identify the factors determining the severity of this syndrome manifestations.

Material and Methods - Systematic review and meta-analysis were performed according to the guidelines of Preferred Reporting Items for Systematic Reviews and Meta-Analyses (PRISMA). The study selected publications that included the functional results of treatment of patients operated for rectal cancer. Functional impairments were assessed according to the international LARS Score. Statistical analysis was performed using the inverse-variance weighted average method (IVW) with calculation of the odds ratio logarithm and standard error of the mean.

Results - After a critical search and analysis of all literature sources, eight studies were found suitable for meta-analysis. In total, 1042 patients (796 men and 246 women) were included into statistical analysis, 409 of which (39.2\%) had symptoms of major LARS. Chemotherapy was performed on 637 (62.5\%) patients, while 568 subjects (55.5\%) underwent radiation therapy, and anastomotic leaks were described in 89 (8.5\%) people. According to the results of the meta-analysis, statistically significant factors were: preventative ostomy $(\mathrm{OR}=3.32,95 \% \mathrm{Cl}$ 1.99-5.55, $\mathrm{p}<0.00001)$, chemotherapy (OR=1.98, 95\% Cl 1.23-3, 19, $\mathrm{p}=0.005)$, radiation therapy (OR=5.00, 95\% Cl 2.73$9.13, \mathrm{p}<0.00001)$, anastomotic leaks (OR=2.93, 95\% $\mathrm{Cl} 2.30-3,73, \mathrm{p}<0.00001)$, anal verge distance from anastomosis site $(\mathrm{OR}=2.61,95 \% \mathrm{Cl}$ 1.47-4.62, $\mathrm{p}=0.001)$.

Conclusion - The results of our meta-analysis allowed us identifying the group of rectal cancer patients most vulnerable to LARS. The risk of developing severe functional disorders is significantly higher in patients with low colorectal anastomosis, as well as in patients undergoing neoadjuvant radiation therapy.

Keywords: rectal cancer, low anterior resection syndrome, incontinence.

Cite as Khomyakov EA, Nafedzov IO, Fomenko OYu, Alekseyev MV, Frolov SA, Tchernyshov SV, Rybakov EG. Risk factors for major low anterior resection syndrome: Meta-analysis and systematic literature review. Russian Open Medical Journal 2021; 10 : e0113.

Correspondence to Islam O. Nafedzov. Address: A.N. Ryzhikh National Medical Research Center of Coloproctology, 2 Salyam Adil St., Moscow 123423, Russia. Phone: +74991990409. E-mail: info@gnck.ru.

\section{Introduction}

Low anterior resection syndrome (LARS) is a multifactorial complex of symptoms, characterized by frequent bowel movements (up to 6 times a day, or more), prolonged and incomplete bowel movements, urgent urge to defecate and anal incontinence of varying severity, resulting from the loss of reservoir and evacuation function of the rectum after surgery [1, 2].

The incidence of LARS after low anterior rectal resection varies from 25 to $90 \%$ [1]. This problem leads to a deterioration in the quality of life and impedes the social adaptation of patients, while their quality of life directly depends on the severity of LARS [3].
Despite the complexity of the syndrome and the severity of its manifestations, a scale for assessing the severity of low anterior resection syndrome (LARS score) was developed to standardize and objectify the loss of quality of life, which was validated in Russia as well [4].

Considering that functional impairments after low anterior rectal resection are caused by the loss of a functionally significant part of the rectum, theoretically, a minor LARS is a natural and somewhat expected result, which could be evaluated as satisfactory. That is why, in order to exclude unobvious consequences, the area of our scientific interests was focused upon the risk factors for the development of major LARS. 


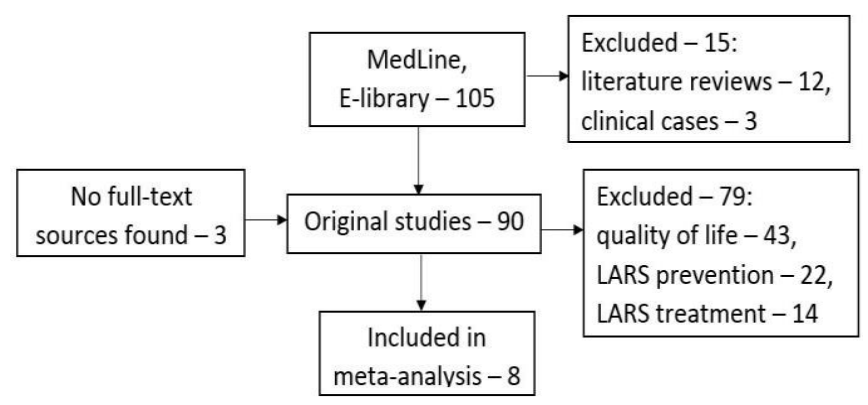

Figure 1. Systematic literature search flowchart

Since almost every patient encounters the problems of impaired evacuation function after low anterior rectal resection (LAR), it seems relevant to search for the category of patients most prone to major LARS, as well as to search for factors that determine the severity of manifestations of this syndrome.

Due to the prevalence and urgency of the problem, the number of studies, devoted to identifying risk factors for LARS, is growing; accordingly, we conducted a systematic review and meta-analysis of the published data on risk factors for this complex of symptoms.

\section{Material and Methods}

The systematic review and meta-analysis were performed according to the guidelines of Preferred Reporting Items for Systematic Reviews and Meta-Analyses (PRISMA) [5].

Publications for analysis were searched for in the electronic databases Medline and E-library using the following keywords: "low anterior resection syndrome», "LARS», "colorectal cancer», "rectal cancer», "colorectal surgery», "fecal incontinence», «functional outcomes». Studies, dedicated to the analysis of risk factors for low anterior resection syndrome, published in Russian and English languages, were selected for the meta-analysis without restrictions on the date or status of publication. After compiling the request, we found 105 articles in the PubMed database. No articles matching the inclusion criteria were found in the E-library database. At the next stage of the search, we excluded literature reviews, non-original articles, which resulted in 90 original studies. At the third stage of our search, a critical analysis of discovered sources was carried out, as a result of which eight full-text studies were selected as suitable for the metaanalysis goal. Functional impairments were assessed in accordance with the international LARS Score. A systematic literature search is presented in Figure 1.

\section{Statistical analysis}

Statistical analysis was performed using the free-of-charge Review Manager 5.3 software for MacOS. For binary values, the odds ratios were calculated using the Peto method. Taking into account that not all studies presented binary values, the analysis was carried out by the inverse-variance weighted average method (IVW) with calculation of the odds ratio logarithm and standard error of the mean.

\section{Evaluating quality of studies included into meta-analysis}

All studies included in the analysis were reviewed according to the Newcastle-Ottawa Scale (NOS) system for assessing the quality of comparative studies [6] (Table 1). The publications included in the meta-analysis corresponded to indicators of 7 stars and above, which suggested high quality of selected studies. It is important to note that all of the studies selected were retrospective, which is typical of factor analysis.

\section{Results}

All selected studies included the data on cumulative amount of 1042 patients operated for rectal cancer: 796 men and 246 women, 409 (39.2\%) of which had symptoms of major LARS. Chemotherapy was performed on 637 (62.5\%) patients, while 568 $(55.5 \%)$ underwent radiation therapy, and postoperative complications in the form of anastomotic leaks were described in 89 (8.5\%) people.

\section{Gender}

In all eight studies, the effect of gender on the risk of major manifestations of LARS was assessed. Despite the obvious bias in favor of men in the studies included into our meta-analysis, there were no statistically significant gender-based differences in the risk of developing a major LARS (OR=1.04, Cl 0.74-1.47, $\mathrm{p}=0.82$ ) (Figure 2).

\section{Age}

Age as a risk factor for a major LARS was analyzed in seven studies. There were no significant differences at the cut-off level of 70 years of age during the meta-analysis $(\mathrm{OR}=0.99,95 \% \mathrm{Cl} 0.95$ $1.02, \mathrm{p}=0.44$ ) (Figure 3 ).

\section{Body mass index}

Body mass index (BMI) was assessed in three studies $[7,9,14]$. An elevated body mass index was not associated with the risk of developing a major LARS. (OR=0.99, 95\% Cl 0.90-1.08, $\mathrm{p}=0.80$ ) (Figure 4).

\section{Preventative ostomy}

The factor of preventative ostomy in the occurrence of a major LARS was analyzed in eight studies. The meta-analysis showed that the formation of a preventative stoma was associated with a three-fold increase in the risk of developing severe functional problems after the surgery $(\mathrm{OR}=3.32,95 \% \mathrm{Cl}$ 1.99-5.55, $\mathrm{p}<0.00001$ ) (Figure 5).

\section{Chemotherapy}

In 7 out of 8 studies, the effect of chemotherapy on the risk of a major LARS development has been studied [7,8,10-14]. As the meta-analysis results implied, chemotherapy increased two-fold the risk of major LARS symptoms (OR=1.98, 95\% Cl 1.23-3.19, $\mathrm{p}=0.005$ ) (Figure 6).

\section{Radiation therapy}

In all eight studies, the role of radiation therapy in the occurrence of functional problems was investigated. Radiation therapy significantly increased the risk of functional problems after the treatment $(\mathrm{OR}=5.00,95 \% \mathrm{Cl} 2.73-9.13, \mathrm{p}<0.00001)$ (Figure 7). 
Table 1. Characteristics of studies included in the meta-analysis

\begin{tabular}{|c|c|c|c|c|c|c|c|}
\hline Author & Year & Country & Type & Median value & Quality score & $N$ & Major LARS (n) \\
\hline Lai S. [7] & 2018 & China & Retrospective & $40.2 \mathrm{mo}$ & 7 & 220 & 119 \\
\hline Ekkarat P. [8] & 2018 & Thailand & Retrospective & 12 mo. & 8 & 129 & 23 \\
\hline Wierdak M. [9] & 2018 & Poland & Retrospective & $6 \mathrm{mo}$ & 7 & 56 & 15 \\
\hline Nuytens F. [11] & 2018 & Germany & Retrospective & $38 \mathrm{mo}$. & 7 & 100 & 51 \\
\hline Jimenez-Gomez L.M. [12] & 2017 & Spain & Retrospective & none & 7 & 184 & 104 \\
\hline Hughes D.L. [13] & 2017 & Germany & Retrospective & none & 7 & 68 & 38 \\
\hline
\end{tabular}

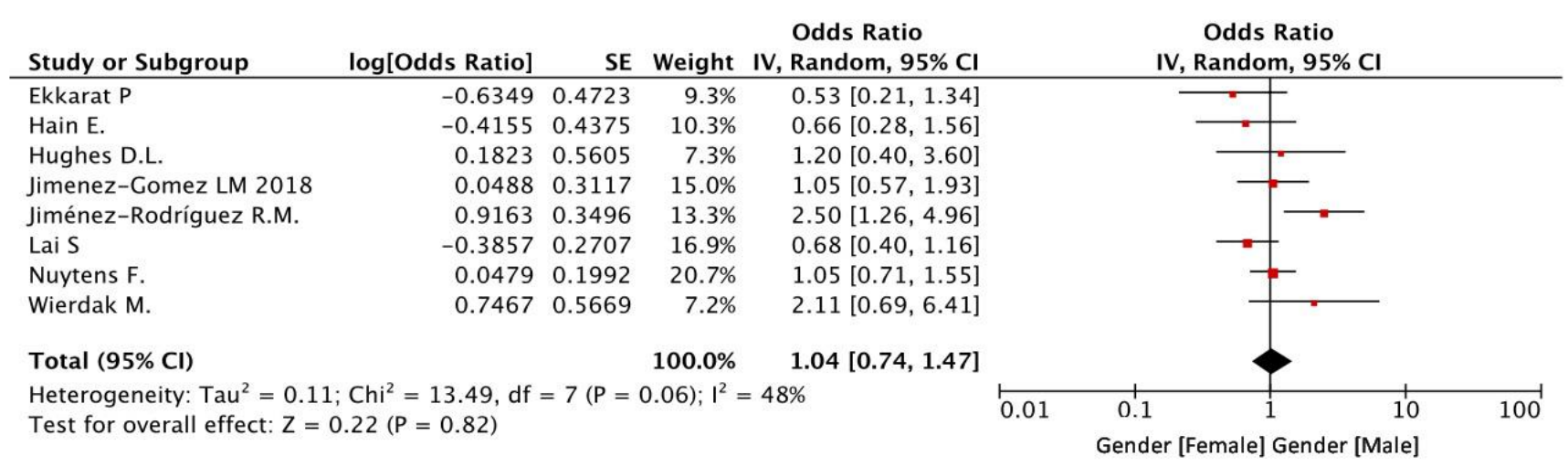

Figure 2. Gender as a risk factor for LARS.

Odds Ratio

Study or Subgroup

Ekkarat $P$

Hain E.

Hughes D.L.

Jimenez-Gomez LM 2018

Lai S

Nuytens F.

Wierdak M
log[Odds Ratio]

$-0.71330 .6392$

$-0.69310 .4675$

$-0.0305 \quad 0.016$

$\begin{array}{ll}-0.3857 & 0.2707\end{array}$

$0.019 \quad 0.02$

$\begin{array}{ll}-0.0202 & 0.0267\end{array}$

$\begin{array}{ll}-0.1278 & 0.456\end{array}$

Weight IV, Random, 95\% CI

$0.2 \% \quad 0.88[0.36,2.15]$

$0.1 \% \quad 0.49[0.14,1.72]$

$0.2 \% \quad 0.50[0.20,1.25]$

$39.3 \% \quad 0.97[0.94,1.00]$

$0.5 \% \quad 0.68[0.40,1.16]$

$33.8 \% \quad 1.02[0.98,1.06]$

$26.0 \% \quad 0.98[0.93,1.03]$

Total $(95 \% \mathrm{CI})$

$100.0 \%$

Heterogeneity: $\mathrm{Tau}^{2}=0.00 ; \mathrm{Chi}^{2}=9.09, \mathrm{df}=6(\mathrm{P}=0.17) ; \mathrm{I}^{2}=34 \%$

Test for overall effect: $Z=0.78(P=0.44)$

$0.99[0.95,1.02]$

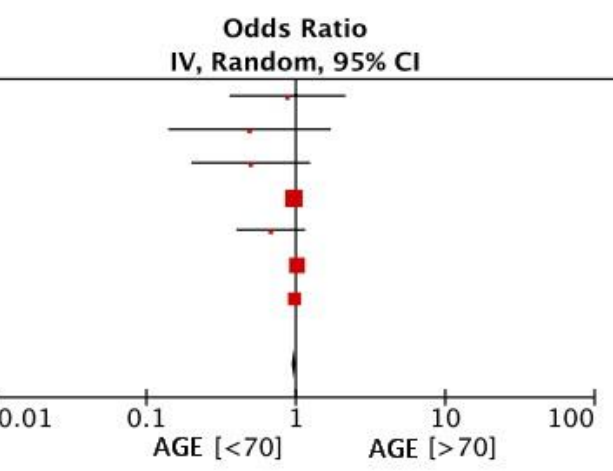

Figure 3. Age as a risk factor for LARS.

\section{Anastomotic leaks}

The influence of anastomotic leaks on functional consequences has been assessed in five studies [7, 11-14]. This complication was a statistically significant risk factor for a major LARS (OR=2.93, 95\% Cl 2.30-3.73, p<0.001) (Figure 8).

\section{Anal verge distance}

Seven studies [7-9, 11-14] evaluated the effect of the distance between the anastomosis site and the anal verge on the risk of symptoms of LARS. In patients with anastomosis located below 5 $\mathrm{cm}$ from the outer edge of the anal canal, the functional results were 2.6-fold worse $(\mathrm{OR}=2.61,95 \% \mathrm{Cl} 1.47-4.62, \mathrm{p}=0.001)$ (Figure 9).

\section{Anastomosis type}

Two studies [11, 14] compared the effect of a side-to-end anastomosis with an end-to-end anastomosis on functional outcomes. However, no statistical significance was obtained (OR=1.81, 95\% Cl 0.55-5.92, $\mathrm{p}=0.33$ ) (Figure 10).

\section{Timing of stoma closure}

In three studies [7, 12, 13], the effect of the timing of stoma closure on functional results was assessed. The timing of reconstructive surgery exceeding 6 months was not associated with the risk of developing a major LARS, and when comparing these studies, we did not obtain any statistical difference (OR=1.02, 95\% Cl 0.91-1.14, $\mathrm{p}=0.79$ ) (Figure 11).

\section{Discussion}

Low anterior resection syndrome is a socially significant problem that leads to disability and a deterioration in the patient quality of life $[3,14]$. The identification of risk factors for LARS is currently a relevant and promising course of research, which directly affects the growing number of studies dedicated to this problem. 


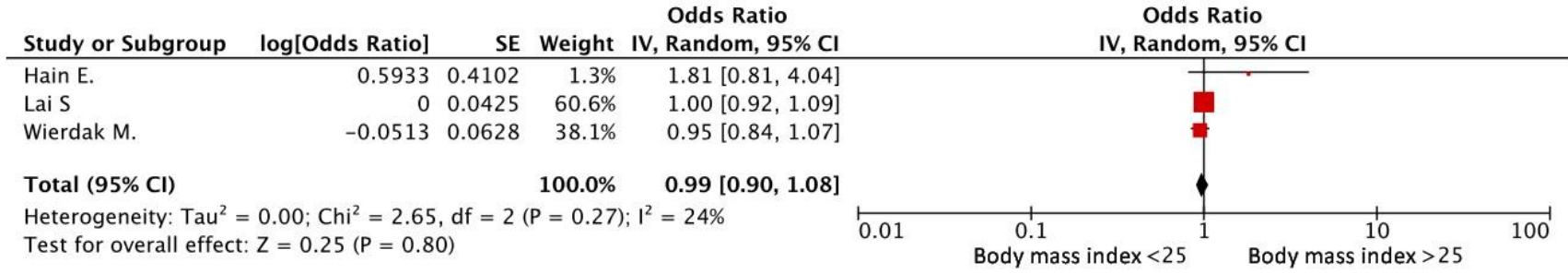

Figure 4. BMI as a risk factor for LARS.

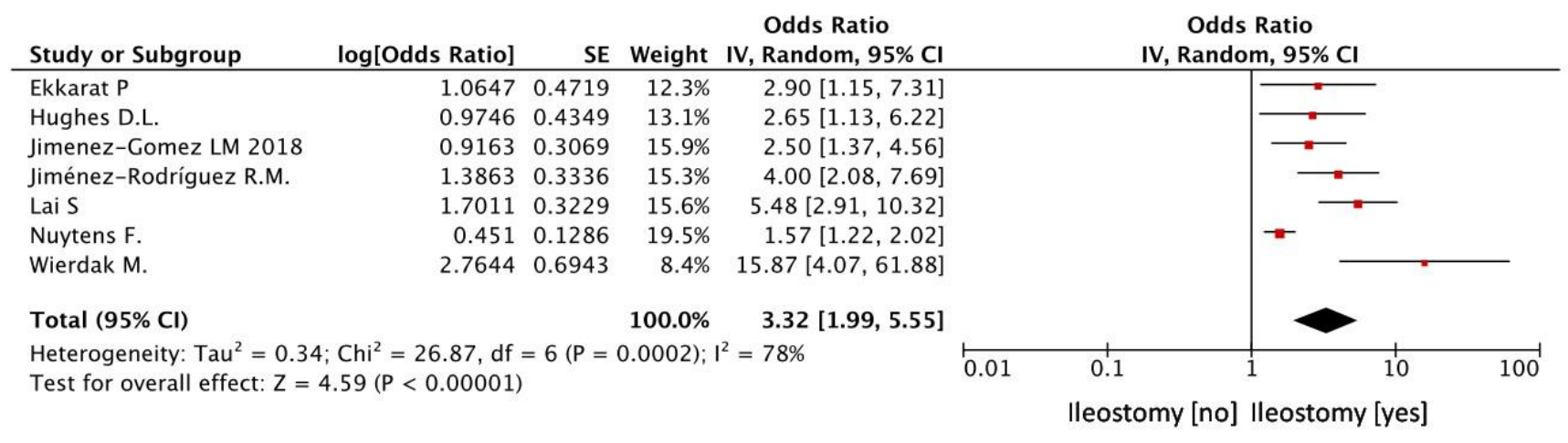

Figure 5. Preventative ostomy as a risk factor for LARS.

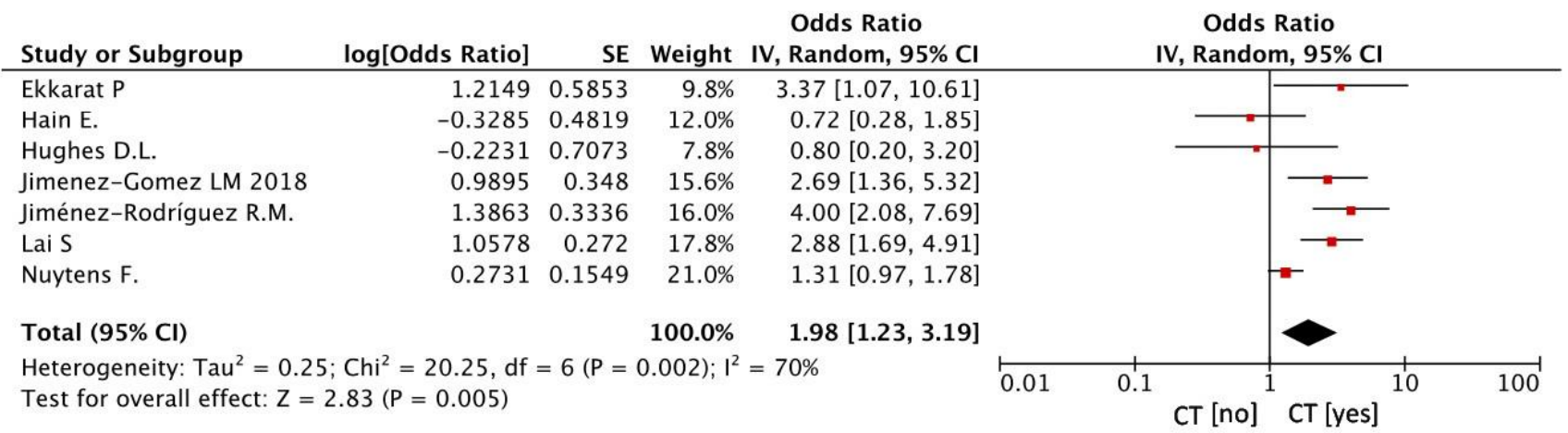

Figure 6. Chemotherapy (CT) as a risk factor for LARS.

According to the meta-analysis results, radiation therapy adversely affects the severity of LARS manifestations ( $O R=5.00$, $95 \% \mathrm{Cl}=2.73-9.13, \mathrm{p}<0.001)$, regardless of the characteristics of the surgical intervention, having a direct effect on functional outcomes of the treatment. For example, 33 non-operated patients with complete response after radical dose of chemoradiotherapy for malignant rectal neoplasms were involved in a study by Van Der Sande, et al. [15]. Two years after the treatment, 11 patients had pronounced manifestations of the syndrome of low anterior resection (30-39 points), and 10 patients had minor LARS (21-29 points).

The influence of body mass index on the functional results of sphincter-preserving treatment was not confirmed in the process of meta-analysis. However, this factor was described as significant in some publications: for example, in the study by Bohlok et al. [16], which included 43 patients after low anterior resection with a total mesorectal excision, 31 (72.1\%) had signs of severe functional impairment, while $\mathrm{BMI}>30 \mathrm{~kg} / \mathrm{m}^{2}$ was the only statistically significant risk factor for major LARS $(p=0.047)$, which, nonetheless, could be detected due to a small sample size of patients in that study.

Almost all authors of the studies included in our meta-analysis distinguished the factor of preventative ostomy as unfavorable in terms of functional results. Similarly, in the meta-analysis by Keane et al. [17], summarizing the results of treating 227 patients from four studies (three of which were randomized), compared bowel function and quality of life in patients after LAR with and without formation of a temporary stoma. According to the results of our meta-analysis, ileostomy was associated with a two-fold risk of developing LARS (OR=1.96, 95\% Cl 1.1-3.5, $\mathrm{p}=0.02)$. It is important to note that our study has also assessed an impact of the stoma closure timing. With an average follow-up of 50 months, there were no statistically significant differences in quality of life in the patients with an early closure (two weeks) and conventional closure (LARS $73 \%$ versus $60 \%, p=0.3$ ). No statistical significance for the factor of the stoma closure timing was established by our meta-analysis (OR=1.02, 95\% Cl 0.91-1.14, $\mathrm{p}=0.79)$. 


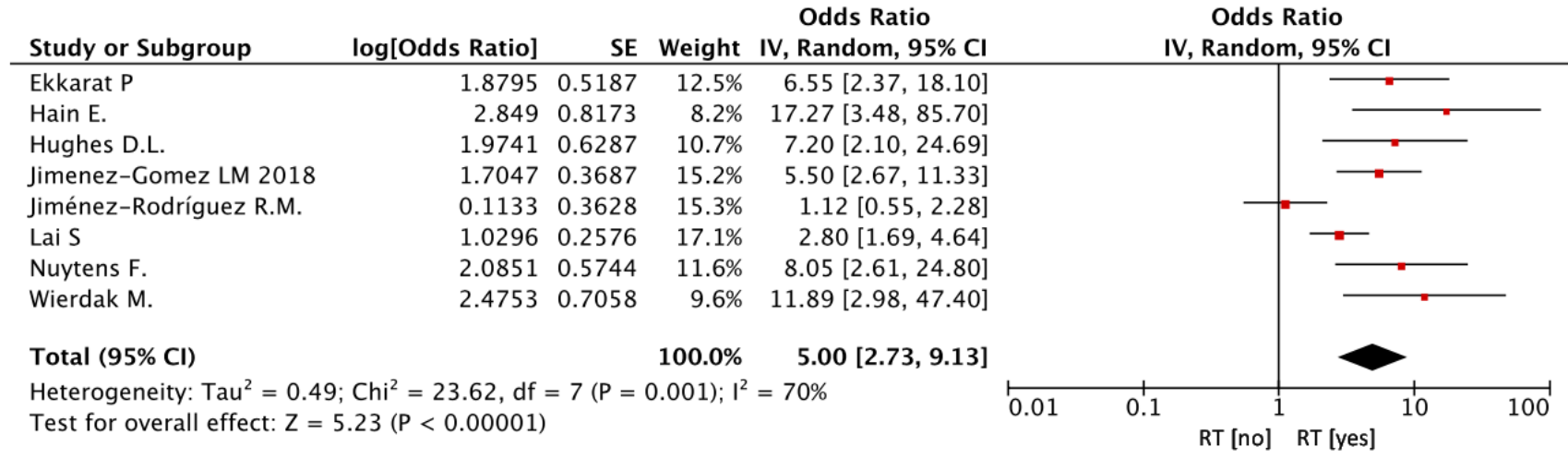

Figure 7. Radiation therapy (RT) as a risk factor for LARS.

Odds Ratio

\begin{tabular}{|c|c|c|c|c|}
\hline Study or Subgroup & log[Odds Ratio] & SE & Weight & IV, Random, 95\% CI \\
\hline Hain E. & 1.203 & 0.4918 & $6.3 \%$ & $3.33[1.27,8.73]$ \\
\hline Hughes D.L. & 1.2238 & 1.0919 & $1.3 \%$ & $3.40[0.40,28.90]$ \\
\hline Jimenez-Gomez LM 2018 & 0.27 & 0.534 & $5.3 \%$ & $1.31[0.46,3.73]$ \\
\hline Lai S & 1.1725 & 0.4683 & $6.9 \%$ & $3.23[1.29,8.09]$ \\
\hline Nuytens F. & 1.1067 & 0.1375 & $80.2 \%$ & $3.02[2.31,3.96]$ \\
\hline Total $(95 \% \mathrm{Cl})$ & & & $100.0 \%$ & $2.93[2.30,3.73]$ \\
\hline
\end{tabular}

Test for overall effect: $Z=8.72(P<0.00001)$

Figure 8. Anastomotic leaks as a risk factor for LARS

Odds Ratio

Study or Subgroup

log[Odds Ratio] SE Weight IV, Random, 95\% Cl

$\begin{array}{lllll}\text { Ekkarat P } & 1.9713 & 0.6496 & 11.3 \% & 7.18[2.01,25.65]\end{array}$

Hain E.

Hughes D.L.

Jimenez-Gomez LM 2018

Lai S

Nuytens F.

Wierdak M.

$1.0986 \quad 0.4189 \quad 16.7 \%$

$3.00[1.32,6$

$\begin{array}{lll}0.47 & 0.5004 & 14.6 \%\end{array}$

$\begin{array}{lll}1.16 & 0.3457 \quad 18.8 \%\end{array}$

$\begin{array}{lll}0.6931 & 0.7073 \quad 10.2 \%\end{array}$

$1.60[0.60,4.27]$

$3.19[1.62,6.28]$

$2.00[0.50,8.00]$

$0.1985 \quad 0.1842$

$23.2 \%$

$1.22[0.85,1.75]$

$2.8332 \quad 1.1289$

Odds Ratio IV, Random, 95\% Cl

Total $(95 \% \mathrm{Cl})$ $100.0 \% \quad 2.61[1.47,4.62]$

Heterogeneity: $\mathrm{Tau}^{2}=0.33 ; \mathrm{Chi}^{2}=17.24, \mathrm{df}=6(\mathrm{P}=0.008) ; \mathrm{I}^{2}=65 \%$

Test for overall effect: $Z=3.29(P=0.001)$

Figure 9. Anal verge distance from anastomosis as a risk factor for LARS

Odds Ratio

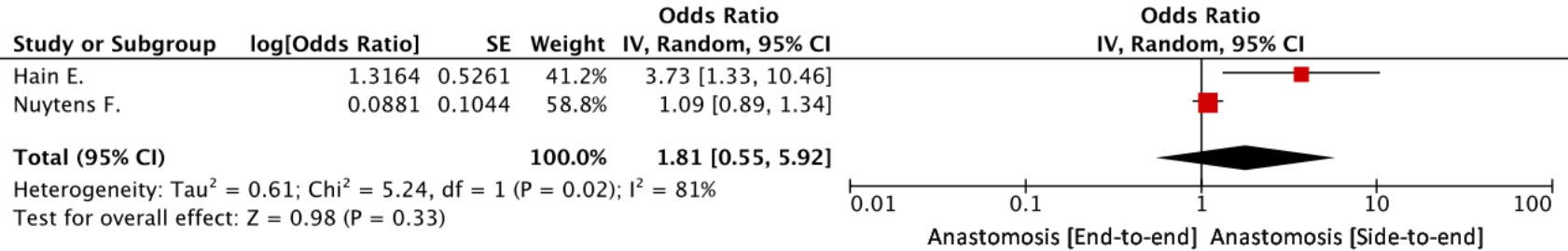

Figure 10. Anastomosis type as a risk factor for LARS

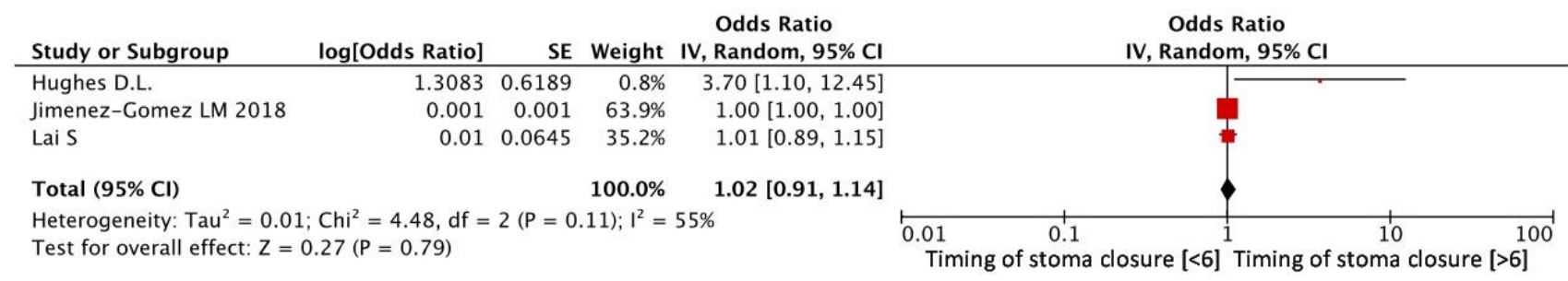

Figure 11. Timing of stoma closure as a risk factor for LARS 
We think that the factor of preventative stoma formation should be considered in combination with other significant risk factors for functional loss after low anterior rectal resections. Thus, in the meta-analysis published by Croese et al. [18], summarizing the results of 11 studies, a comprehensive analysis of the LARS prevalence of varying severity and a systematic review of the literature dedicated to the search for LARS risk factors were carried out. The prevalence of major LARS was found at the level of $42 \%(95 \% \mathrm{Cl} 35-48)$, while a systematic review of risk factors showed that radiation therapy and the distance between the tumor site (and, consequently, anastomosis site) and the anal verge were the most frequently detected and significant risk factors for the development of a major LARS, whereas the negative impact of preventative ileostomy was demonstrated in just four of eleven studies [18]. Despite the lack of statistical processing of the resulting risk factors, the outcomes of the metaanalysis by Croese A.D. et al. were supported by our findings, which implied the reproducibility of our data.

It is worth noting that preventative ostomy reduces the severity of the clinical manifestations (rather than just the incidence) of hypothetical anastomotic leaks [19]. Clinical anastomotic leaks, as a factor, were evaluated in the study by Hain et al., which included 46 patients after laparoscopic LAR with anastomotic leaks. Statistically significant differences were obtained for the major LARS incidence between the group of patients with clinically significant (44\%) and clinically insignificant (17\%) anastomotic leaks $(p=0.04)$ [14]. According to our data, anastomotic leaks were associated with an almost threefold increase in the risk of functional problems, which confirmed the indirectness of the preventative ostomy factor.

Thus, the problem of unsatisfactory functional results after surgery for rectal cancer remains largely unresolved. Investigation of risk factors and prediction of possible functional problems could reduce LARS incidence by rejecting sphincter-preserving surgeries in patients with obvious unfavorable functional results, and would also allow identifying a promising group of patients for the implementation of rehabilitation program. Battersby N.J. et all [21] presented the first online tool for the preoperative prediction of post-operative functional disorders. This tool is an online calculator; it consists of six items, accounting for age, gender, partial or total mesoretal excisiondistance of a tumor site from the anal verge, the presence of a stoma, and radiation therapy. After entering the data, the program calculates the number of predicted points on the LARS Score.

\section{Conclusion}

The results of performed meta-analysis permitted to identify the most vulnerable group of patients with rectal cancer and a prospect to undergo low anterior rectal resection. The risk of severe functional impairment was significantly higher in patients with low ( $<5 \mathrm{~cm}$ from the anal verge) colorectal anastomosis, as well as in patients undergoing neoadjuvant radiation therapy. The issue of choosing the scope of surgical treatment in this category of patients should be discussed more scrupulously, followed by the development of an individual program of functional rehabilitation.

\section{Ethical approval}

This manuscript does not contain any research involving human or animal subjects carried out by any of the authors.

\section{Conflict of interests}

The authors state no financial, ethical, or other conflict of interests.

\section{Study limitations}

Presented meta-analysis is limited by the impossibility of performing logistic regression to identify independent risk factors for severe LARS.

\section{References}

1. Bryant $\mathrm{CL}$, Lunniss PJ, Knowles $\mathrm{CH}$, Thaha $\mathrm{MA}$, Chan $\mathrm{CL}$. Anterior resection syndrome. Lancet Oncol 2012; 13(9): 403-408. https://doi.org/10.1016/S1470-2045(12)70236-X

2. Bartlett L, Sloots K, Nowak M, Ho YH. Biofeedback therapy for symptoms of bowel dysfunction following surgery for colorectal cancer. Tech Coloproctol 2011; 15(3): 319-326. https://doi.org/10.1007/s10151-011-0713-5.

3. Juul T, Ahlberg M, Biondo S, Espin E, Jimenez LM, Matzel KE, et al. Low anterior resection syndrome and quality of life: an international multicenter study. Dis Colon Rectum 2014; 57(5): 585-591. https://doi.org/10.1097/DCR.0000000000000116.

4. Shelygin YuA, Pikunov DYu, Khomyakov EA, Rybakov EG. Validation of the russian translation of the low anterior resection syndrome score. Koloproktologia 2016; (4): 7-14. Russian. https://doi.org/10.33878/2073-7556-2016-0-4-7-14.

5. Liberati A1, Altman DG, Tetzlaff J, Mulrow C, Gøtzsche PC, loannidis JP, et al. The PRISMA statement for reporting systematic reviews and meta-analyses of studies that evaluate healthcare interventions: explanation and elaboration. BMJ 2009; 339: b2700. https://doi.org/10.1136/bmj.b2700.

6. Wells GA, Shea B, O'Connell D, Peterson J, Welch V, Losos M, et al. The Newcastle-Ottawa Scale (NOS) for assessing the quality of nonrandomized studies in meta-analyses. 2015 http://www.ohri.ca/programs/clinical epidemiology/oxford.asp.

7. Sun W, Dou R, Chen J, Lai S, Zhang C, Ruan L, et al. Impact of LongCourse Neoadjuvant Radiation on Postoperative Low Anterior Resection Syndrome and Quality of Life in Rectal Cancer: Post Hoc Analysis of a Randomized Controlled Trial. Ann Surg Oncol 2019; 26(3): 746-755. https://doi.org/10.1245/s10434-018-07096-8.

8. Ekkarat $\mathrm{P}$, Boonpipattanapong $\mathrm{T}$, Tantiphlachiva $\mathrm{K}$, Sangkhathat $\mathrm{S}$. Factors determining low anterior resection syndrome after rectal cancer resection: A study in Thai patients. Asian J Surg 2016; 39(4): 225-231. https://doi.org/10.1016/j.asjsur.2015.07.003.

9. Nowakowski MM, Rubinkiewicz M, Gajewska N, Torbicz G, Wysocki M, Malczak $P$, et al. Defunctioning ileostomy and mechanical bowel preparation may contribute to development of low anterior resection syndrome. Wideochir Inne Tech Maloinwazyjne 2018; 13(3): 306-314. https://doi.org/10.5114/wiitm.2018.76913.

10. Jiménez-Rodríguez RM, Segura-Sampedro JJ, Rivero-Belenchón I, Díaz Pavón JM, García Cabrera AM, Vazquez Monchul JM, et al. Is the interval from surgery to ileostomy closure a risk factor for low anterior resection syndrome? Colorectal Dis 2017; 19(5): 485-490. https://doi.org/10.1111/codi.13524

11. Nuytens F, Develtere D, Sergeant G, Parmentier I, D'Hoore A, D'Hondt $M$. Perioperative radiotherapy is an independent risk factor for major LARS: a cross-sectional observational study. Int J Colorectal Dis 2018; 33(8): 1063-1069. https://doi.org/10.1007/s00384-018-3043-5.

12. Jimenez-Gomez LM, Espin-Basany E, Trenti L, Martí-Gallostra M, Sánchez-García JL, Vallribera-Valls F, et al. Factors associated with low anterior resection syndrome after surgical treatment of rectal cancer. $\begin{array}{llll}\text { Colorectal Dis 2017; } & \text { 195-200. }\end{array}$ https://doi.org/10.1111/codi.13901.

13. Hughes DL, Cornish J, Morris C. Functional outcome following rectal surgery-predisposing factors for low anterior resection syndrome. Int $J$ Colorectal Dis 2017; 32(5): 691-697. https://doi.org/10.1007/s00384017-2765-0. 
14. Hain E, Manceau G, Maggiori L, Mongin C, Prost À la Denise J, Panis Y. Bowel dysfunction after anastomotic leakage in laparoscopic sphincter-saving operative intervention for rectal cancer: A casematched study in 46 patients using the Low Anterior Resection Score.

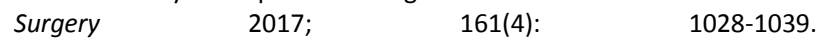
https://doi.org/10.1016/i.surg.2016.09.037.

15. van der Sande ME, Hupkens BJP, Berbée $M$, van Kuijk SMJ, Maas $M$ Melenhorst J, et al. Impact of radiotherapy on anorectal function in patients with rectal cancer following a watch and wait programme. Radiother Oncol 2019; 132: $19-84$. https://doi.org/10.1016/i.radonc.2018.11.017.

16. Bohlok A, Mercier C, Bouazza F, Galdon MG, Moretti L, Donckier V, et al. The burden of low anterior resection syndrome on quality of life in patients with mid or low rectal cancer. Support Care Cancer 2020; 28(3): 1199-1206. https://doi.org/10.1007/s00520-019-04901-2.

17. Keane C, Sharma P, Yuan L, Bissett I, O'Grady G. Impact of temporary ileostomy on long-term quality of life and bowel function: a systematic review and meta-analysis. ANZ J Surg 2020; 90(5): 687-692. https://doi.org/10.1111/ans.15552.

18. Croese AD, Lonie JM, Trollope AF, Vangaveti VN, Ho YH. A metaanalysis of the prevalence of Low Anterior Resection Syndrome and systematic review of risk factors. Int I Surg 2018; 56: 234-241. https://doi.org/10.1016/j.ijsu.2018.06.031.

19. Rybakov EG, Shelygin YuA, Taraso MA, Alekseev MV, Kashnikov VN. Impact of anastomotic leakage on outcomes in patients with rectal cancer. Pelvic Surgery and Oncology 2018; 8(2): 18-23. Russian. https://doi.org/10.17650/2220-3478-2018-8-2-18-23.

20. Battersby NJ, Bouliotis G, Emmertsen KJ, Juul T, Glynne-Jones R, Branagan G, et al. Development and external validation of a nomogram and online tool to predict bowel dysfunction following restorative rectal cancer resection: The POLARS score. Gut 2018; 67(4): 688-696. https://doi.org/10.1136/gutjnl-2016-312695.

Authors:

Evgeny A. Khomyakov - MD, PhD, Research Scientist, Division of Oncological Proctology, A.N. Ryzhikh National Medical Research Center of Coloproctology; Instructor, Department of Coloproctology, Russian Medical Academy of Continuing Professional Education, Moscow, Russia. https://orcid.org/0000-0002-3399-0608.

Islam O. Nafedzov - Post-graduate Student, Division of Oncological Proctology, Coloproctologist at the Consultative Polyclinic, A.N. Ryzhikh National Medical Research Center of Coloproctology, Moscow, Russia. https://orcid.org/0000-0002-0030-5897.

Oksana Y. Fomenko - MD, DSc, Head of the Laboratory of Clinical Pathophysiology, A.N. Ryzhikh National Medical Research Center of Coloproctology, Moscow, Russia. https://orcid.org/0000-0001-9603-6988.

Mikhail V. Alekseyev - MD, PhD, Senior Research Scientist, Division of Oncological Proctology, A.N. Ryzhikh National Medical Research Center of Coloproctology; Associate Professor, Department of Coloproctology, Russian Medical Academy of Continuing Professional Education, Moscow, Russia. https://orcid.org/0000-0001-5655-6567.

Sergey A. Frolov - MD, DSc, Professor, Laureate of the Prize of the Russian Federation Government in the Field of Science and Technology, Deputy Director for Research, A.N. Ryzhikh National Medical Research Center of Coloproctology, Moscow, Russia. https://orcid.org/0000-0002-4697-2839.

Stanislav V. Tchernyshov - MD, DSc, Principal Research Scientist, Division of Oncological Proctology, A.N. Ryzhikh National Medical Research Center of Coloproctology, Moscow, Russia. https://orcid.org/0000-0002-6212$\underline{9454}$

Evgeny G. Rybakov - MD, DSc, Professor of the Russian Academy of Sciences, Laureate of the Prize of the Russian Federation Government in the Field of Science and Technology, Head of the Department of Oncological Proctology, A.N. Ryzhikh National Medical Research Center of Coloproctology, Moscow, Russia. https://orcid.org/0000-0002-3919-9067. 